\title{
Mitochondrial cytopathy. A multisystem disorder with ragged red fibres on muscle biopsy
}

\author{
J EGGER, B D LAKE, AND J WILSON
}

\begin{abstract}
Department of Neurology and Department of Histopathology, The Hospital for Sick Children and Institute of Child Health, London
\end{abstract}

SUMMARY Thirteen children with abnormal mitochondria in muscle tissue, and a progressive neurological disorder that affected the cerebrum, cerebellum, extrapyramidal system, vestibular system, retina, upper motor neuron, lower motor neuron, and musculature, are reported. Other signs and symptoms were short stature, diabetes mellitus, cardiopathy, hypoplastic anaemia, glomerulopathy, and renal tubular dysfunction. These symptoms may occur singly or in various combinations and the manifestation may differ even within the same family. The most common clinical picture was that of 'ophthalmoplegia plus'. Occurrence in relatives varied from isolated symptoms to the complete syndrome with 'ragged red fibres' and is not inconsistent with an autosomal dominant mode of inheritance with variable expressivity. Theories for the pathophysiological basis of this syndrome are discussed and the literature reviewed.

In 1972 Olson et al. ${ }^{1}$ reported 7 cases of oculocraniosomatic neuromuscular disease, in whom skeletal muscle biopsy specimens showed, when using the modified Gomori trichrome stain, accumulation of red staining material in the subsarcolemmal and intermyofibrillar regions of irregularly shaped fibres. They coined the term 'ragged red fibres' and demonstrated with the aid of oxidative enzyme stains and electron microscopical examination that such areas consisted of aggregates of abnormal mitochondria mainly within type I fibres. Clinical findings in their patients were ptosis, extraocular muscle weakness, ataxia, deafness, heart conduction defects, and raised cerebrospinal fluid (CSF) protein.

Earlier Drachman in $1968^{2}$ had introduced the term 'ophthalmoplegia plus' to cover all syndromes which combined chronic progressive external ophthalmoplegia (CPEO) with 'other changes'; and Kearns and Sayre in $1958^{3}$ gave their eponym to the association of CPEO with cardiac conduction disorders, ataxia, and retinal pigment changes.

Probably the earliest descriptions of this disorder were by Galezowski in $1878^{4}$ and Sandifer in $1946 .^{5}$

Meanwhile further reports appeared, which made it increasingly clear that the mitochondrial dysfunction in ophthalmoplegia plus, exhibited in various tissues, may give rise to many and varied clinical syndromes, even of ophthalmoplegia plus sine ophthalmoplegia. ${ }^{6}$
Symptoms other than those described by Olson et al. ${ }^{1}$ are due to involvement of the nervous system (mental deficiency, ${ }^{7-19}$ epilepsy, ${ }^{9} 111517$ 20-22 spongy degeneration of the brain and spinal cord, 391218 23-28 motor $814172129-32$ and sensory neuropathy, ${ }^{2} 8132129$ $30 \quad 3133-35$ pyramidal $^{2} 101314 \quad 15 \quad 28-3033 \quad 34$ and extrapyramidal signs, ${ }^{19} 293637$ ) the endocrine system (diabetes mellitus, ${ }^{11} \quad 13$ 15 28 34 35 38-43 hypoparathyroidism, ${ }^{8} 4144$ hyperaldosteronism, ${ }^{12}$ hyperthyroidism, ${ }^{24}$ hypogonadism, ${ }^{2} 111427343842$ adrenocorticotrophic hormone deficiency, ${ }^{26}$ short stature with or without growth hormone deficiency, 128 12-16 18-21 2634 40 42-47) the gastrointestinal tract, ${ }^{848} 49$ erythropoiesis, ${ }^{12} 50$ granulopoiesis, ${ }^{12}$ the eye (glaucoma, ${ }^{6}$ cataract, ${ }^{13}$ corneal opacities ${ }^{32}$ ), and of the myocardium. ${ }^{28} 475152$

The ultrastructural abnormalities of the ragged red fibres comprise clusters of large mitochondria, which may contain paracrystalline inclusions commonly having a 'parking lot' arrangement, although others show dense matrices with linear and confluent cristae. ${ }^{1174753-55}$

Because of the abnormal muscle mitochondria ophthalmoplegia plus has been classified with the mitochondrial myopathies, ${ }^{56}$ although similar mitochondrial abnormalities have also been encountered in other tissues including the cerebellum, ${ }^{13}$ skin, ${ }^{16}$ liver, ${ }^{48} 49$ and the myocardium. ${ }^{6} 455257$ No mitochrondrial abnormalities have been noted in the 
peripheral nerves, ${ }^{16}$ but recently ${ }^{31}$ more mitochondria than normal were seen in the unmyelinated Schwann's cell cytoplasm in a biopsy from one patient.

The aetiology of the mitochondrial abnormalities is uncertain and the factors which determine the distribution between various tissues remain unknown.

However, in a limited number of cases an enzyme defect has been identified. Morgan Hughes $e t$ al. ${ }^{58}$ described a deficiency in reducible cytochrome $b$ in a patient with mitochondrial myopathy; Spiro et al. ${ }^{17}$ reported a pronounced reduction of the cytochrome $b$ content in a father and son in whom clinical findings and muscle biopsies were consistent with ophthalmoplegia plus with ragged red fibres; Schotland et al..$^{59}$ found decreased mitochondrial adenosine triphosphatase activity in a patient with proximal muscle weakness, scoliosis, pes cavus, and ragged red fibres; Monnens et al. ${ }^{46}$ found a deficiency of cytochrome $c$ oxidase and a greatly reduced activity of pyruvate dehydrogenase in a patient with growth failure, deafness, and lactic acidosis; Morgan Hughes et al. ${ }^{60}$ described a deficiency of NADH-CoQ reductase in 2 sisters with weakness, exercise intolerance, fluctuating lactic acidaemia, and abnormal muscle mitochondria; Van Biervliet et al. ${ }^{61}$ and DiMauro et al. ${ }^{62}$ measured low values of cytochrome c oxidase in newborn infants with weakness, lactic acidosis, renal tubular dysfunction, and abnormal muscle mitochondria; and Kark and Rodriguez-Budelli63 ${ }^{63}$ reported partial deficiency of lipoamide dehydrogenase in a child with ophthalmoplegia, short stature, weakness, ataxia, and sensory neuropathy in whom a muscle biopsy showed ragged red fibres.

On the other hand, Askanas et al. ${ }^{64}$ observed impaired protein synthesis and growth of mitochondria in muscle cell cultures of patients with ophthalmoplegia plus, and postulated an impaired regulation of the mitochondrial DNA-instructed protein synthesis system.

The prognosis seems to depend mainly on the progressive cardiac conduction defects, if these are present, since several patients have died in their second or third decade due to heart block. ${ }^{31823242642}$ The patients who show the symptoms first in infancy or childhood generally develop more-extensive expression and progression of this multisystem disorder. $^{6}$

Most cases so far described have been sporadic and the theory of a slow virus infection has been proposed $^{14}{ }^{34}$ because in a few cases a febrile illness or even encephalitis or meningitis was diagnosed at the onset of symptoms. Some of the findings-such as raised CSF protein and spongy degeneration of the brain-are consistent with a viral aetiology.

In a few families of reported patients however, a hereditary transmission is apparent which seems to be of an autosomal dominant trait with variable expression of the diseased gene, ${ }^{6} 710172022$ $294647505465-69$ and autosomal recessive in others. ${ }^{915} 454770$

We present 13 children in whom the muscle

Table Summary of some of the clinical features of 13 patients with mitochondrial cytopathy

\begin{tabular}{|c|c|c|c|c|c|c|c|c|c|c|}
\hline \multirow[t]{2}{*}{ Case } & \multirow[t]{2}{*}{ Sex } & \multicolumn{9}{|c|}{ Age (years) at onset } \\
\hline & & Ptosis & Ophthalmoplegia & $\begin{array}{l}\text { Pigmentary } \\
\text { retinopathy }\end{array}$ & Ataxia & $\begin{array}{l}\text { Hearing } \\
\text { loss }\end{array}$ & Neuropathy & Weakness & $\begin{array}{l}\text { Short } \\
\text { stature }\end{array}$ & Other symptoms \\
\hline 1 & $\mathbf{M}$ & 9 & 9 & 8 & 9 & 7 & 9 & 9 & $1-2$ & $\begin{array}{l}\text { Hypoplastic anaemia, } \\
\text { nephropathy at } 11 \text {, } \\
\text { diabetes mellitus at } 9 \text {, } \\
\text { spongiform } \\
\text { leucodystrophy }\end{array}$ \\
\hline 2 & $\mathbf{F}$ & 7 & 7 & - & 9 & - & 9 & - & $\begin{array}{l}\text { Since } \\
\text { infancy }\end{array}$ & - \\
\hline 3 & $\mathbf{M}$ & 5 & 13 & 13 & 13 & 一 & 18 & 14 & $2 \frac{1}{2}$ & Heart block \\
\hline 4 & $\mathbf{F}$ & $12 \frac{1}{2}$ & - & - & $12 \frac{1}{2}$ & - & - & $11 \frac{1}{2}$ & $\begin{array}{l}\text { Since } \\
\text { infancy }\end{array}$ & $\begin{array}{l}\text { Epilepsy at } 17 \frac{1}{2} \\
\text { diabetes mellitus, } \\
\text { mental retardation at } 4\end{array}$ \\
\hline 5 & $\mathbf{F}$ & 9 & 10 & $8 \frac{1}{2}$ & 11 & 一 & 一 & - & $\begin{array}{l}\text { Since } \\
\text { infancy }\end{array}$ & Diabetes mellitus at $6 \frac{1}{2}$ \\
\hline $\begin{array}{l}6 \\
7\end{array}$ & $\mathbf{F}$ & 10 & $11^{3 / 12}$ & $11^{3 / 12}$ & $9 \frac{1}{2}$ & $11^{3 / 12}$ & 一 & - & 2 & Mental retardation \\
\hline $\begin{array}{l}7 \\
8\end{array}$ & $\begin{array}{l}\mathbf{F} \\
\mathbf{F}\end{array}$ & $\begin{array}{l}6 \\
7 \frac{1}{2}\end{array}$ & 13 & $\overline{6}$ & $\begin{array}{r}13 \\
7\end{array}$ & $\overline{5}$ & 二 & $\begin{array}{l}4 \frac{1}{2} \\
7 \frac{1}{2}\end{array}$ & $\begin{array}{l}5 \\
1-2\end{array}$ & $\begin{array}{l}\text { Fanconi's syndrome at } \\
18 \text { months }\end{array}$ \\
\hline 9 & $\mathbf{M}$ & $12 \frac{1}{2}$ & 13 & 8 & 13 & 11 & - & 14 & 5 & \\
\hline 10 & $\mathbf{F}$ & - & - & 14 & $12 \frac{1}{2}$ & $10 \frac{1}{2}$ & 14 & - & $\begin{array}{l}\text { Since } \\
\text { infancy }\end{array}$ & $\begin{array}{c}\text { Epilepsy, mental } \\
\text { retardation }\end{array}$ \\
\hline 11 & $\mathbf{F}$ & 5 & - & 6 & $33 / 12$ & - & 一 & & 12 & Mental retardation \\
\hline $\begin{array}{l}12 \\
13\end{array}$ & $\begin{array}{l}\mathbf{F} \\
\mathbf{M}\end{array}$ & 二 & - & 一 & - & - & 一 & $11 / 12$ & $1-2$ & \\
\hline 13 & $\mathbf{M}$ & - & - & - & - & - & - & $6 / 12$ & 1 & $\begin{array}{l}\text { Nephropathy at } 11 \\
\text { months, mental } \\
\text { retardation }\end{array}$ \\
\hline
\end{tabular}


biopsies showed ragged red fibres and abnormal mitochondria and in whom the clinical findings are consistent with ophthalmoplegia plus or ophthalmoplegia plus sine ophthalmoplegia. We report on the genetics and on the rare renal and haematopoietic involvement.

The case histories of 3 children are given in full in order to give the range of clinical symptoms. The histories of all the children are summarised in the Table.

\section{Patients and investigations}

\section{Case histories.}

\section{Case 3}

Pregnancy and intrauterine movements had been normal; delivery was at term, and birthweight was $2.42 \mathrm{~kg}$. There were no problems in the newborn period and the baby sucked well. Developmental milestones were normal.

In the family history the child's father had bilateral ptosis; 3 siblings and the parents were otherwise healthy and of average height.

There were no worries until the child was aged $2 \frac{1}{2}$ years, when he was first investigated for short stature.

At 5 years he was noted to have drooping of his left, and one year later of his right, eyelid. His bilateral ptosis has worsened since then. At age 13 years he began to suffer from loss of balance and he was found to have a slight tremor and peripheral ataxia. Ocular movements were restricted in all directions and he had mottled pigmentary changes of the retina affecting the central and peripheral regions of each eye. Otherwise cranial nerves showed no abnormalities. Power, tone, and tendon reflexes were normal; plantars were flexor. There was no loss of sensation.

On examination at 14 years, ataxia had become more pronounced and tremor was interfering with his handwriting. He had additional complaints of deteriorating vision and difficulties in getting up stairs, and was found to have proximal weakness. His visual fields were full, visual acuity $6 / 12$ on the right and 6/9 on the left. Academically he was doing very well.

At age 19 years he was seen again and was found to have developed pyramidal signs with brisk knee and ankle jerks and up-going plantars, and impaired sensation to pin prick.

Investigations at age 13 years showed a normal creatine phosphokinase (CK), and normal blood lactate and pyruvate levels. Electromyography (EMG) and nerve conduction velocity were normal. The CSF protein was increased to $130 \mathrm{mg} / 100 \mathrm{ml}$ $(1 \cdot 3 \mathrm{~g} / \mathrm{l})$. The electrocardiogram (ECG) showed an incomplete right-bundle block. The electroencephalogram (EEG) was abnormal with several episodes of 6 and 14 counts per second positive spike phenomena. The electroretinogram (ERG) showed clearly defined responses but their amplitude was reduced.

The patient was thought to have mitochondrial myopathy and a muscle biopsy was performed as described by Claireaux and Lake. ${ }^{71}$ The trichrome stain showed scattered ragged red fibres with increased mitochondrial enzyme activity and increased glycogen content. Both fibre type distribution and percentage composition were normal and there were no other abnormalities.

He was fully investigated for short stature and was found to be growth-hormone deficient. He was treated with growth hormone from his 14th to 19th year, and although his yearly growth rate increased from $3 \cdot 2$ to $5-6 \cdot 5 \mathrm{~cm}$ his height has always remained below the 3 rd centile.

The incomplete right-bundle block progressed during the years to complete right-bundle block and arborisation block, and the implantation of a pace-maker is being considered.

\section{Case 12}

Pregnancy and delivery had been normal and there were normal intrauterine movements. There were no problems in the newborn period and early development was normal. The infant was not thought to be abnormal until age 13 months, when it was noticed that she walked with a waddle. She always had difficulty in getting up from the floor and Gowers's sign was noted from age 2 years. Her arms were not considered to be weak but her mother could not remember seeing her put her hands above her head.

On examination at age 4 years she walked with a waddling gait and had slightly accentuated lumbar lordosis. Gowers's sign was inconsistent, but there was undoubted weakness proximally in both upper and lower limbs. Her tendon reflexes were depressed, her cranial nerves were normal. There was no ataxia, no sensory deficit, and plantars were flexor.

Her CK was $18 \mu \mathrm{mol} / \mathrm{ml}$ (normal 0.8-2.4), her EMG myopathic and suggesting a myositic process, and the muscle biopsy performed in 1970 was not inconsistent with this view, although no frank inflammatory changes could be seen. However, review of the biopsy 10 years later showed typical ragged red fibres in the trichrome preparation. Originally, presuming that the most likely diagnosis was myositis, a therapeutic trial with steroids had been undertaken, and although her strength did not improve, her CK levels became normal. Unfortunately she changed from a cheerful girl to an ill-tempered one and the steroids were stopped after 
a short period. Four weeks after stopping the steroids her CK level was estimated and found to be raised again.

Although suffering from weakness in arms, legs, and trunk she was able to attend a normal school until 14 years old, when she began having increasing difficulty in walking from one classroom to another. Within a few months she was not able to do her hair herself and developed respiratory distress on minimal exertion.

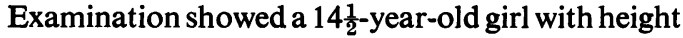
and weight under the 3 rd centile. She was dyspnoeic at rest and her diaphragm was shown to be immobile. There was slight bilateral facial weakness and her speech was slurred. She had difficulty lifting up her head from the bed. Her cranial nerves were normal. There was severe weakness and muscle wasting proximally in the arms and legs. The scapulae showed pronounced winging. Ankle jerks were present, other tendon reflexes were absent, the plantar responses were flexor. Sensation was normal and there was no ataxia.

Investigations at this time showed a normal blood count and erythrocyte sedimentation rate, normal electrolytes, lactate, and pyruvate levels, a moderate respiratory acidosis $\left(\mathrm{pH} 7 \cdot 29, \mathrm{PcO}_{2} 66 \mathrm{mmHg}\right.$ $(8.78 \mathrm{kPa})$, and a raised CK level of $19.4 \mu \mathrm{mol} / \mathrm{ml}$ ). An audiogram and an ECG were normal as was an ERG. Diaphragmatic pressure studies showed a paradoxical oesophageal/abdominal pressure with very little gradient across the diaphragm. The EEG showed some slight abnormality with some excess of irregular slow components in a patchy distribution, and the EMG was myopathic with small and fragmented potentials.

The girl died a few days later in respiratory failure.

\section{Case 13}

This boy was the second child of healthy unrelated parents with no family history of neurological disease or dwarfism; he had been born normally after an uneventful pregnancy with a birthweight of $3.48 \mathrm{~kg}$. He was hypotonic and a slow feeder. All aspects of his development had been delayed, he smiled by 4 weeks, rolled over at 6 months, sat up on his own at 14 months, he never walked alone and never spoke.

His height and weight were below the 3rd centile. His body was covered with fine hair and he had long eyelashes. He had syndactyly of his 2 nd and $3 \mathrm{rd}$ toes, his liver was greatly enlarged, and his testes were not descended. He was very hypotonic, his cranial nerves were normal, his knee jerks were brisk and there was a tendency to scissoring of his legs, plantars being flexor. There was no ataxia.
Since age 11 months he had suffered episodes of drowsiness, vomiting, anorexia, and metabolic acidosis; these occurred every few weeks, mainly provoked by respiratory infections, and lasted a few days.

Investigations showed persistently mildly raised blood pyruvate and lactate levels and hyperalaninaemia; these were not affected by dietary modifications. There was no hyperammonaemia and his glucose levels were always within normal limits. His liver function tests and liver biopsy were normal.

Urinary findings were non-selective proteinuria $(0.8 \mathrm{~g} / 24 \mathrm{~h})$ and numerous hyaline and granular casts. His blood urea concentration was raised $(35.4 \mathrm{mmol} / \mathrm{l}(213 \mathrm{mg} / 100 \mathrm{ml})$, normal 3-6.5 mmol/l) and his glomerular filtration rate (GFR) greatly reduced ( $24 \mathrm{ml} / \mathrm{min}$ per $1.73 \mathrm{~m}^{2}$, normal $\left.89-165\right)$.

There was no lack of bicarbonate reabsorption, and excretion of hydrogen ions was normal. He developed hypocalcaemia, anaemia, and hyperkalaemia. Renin blood levels were found to be normal. No cause for his glomerulopathy was found, immunoglobulins and complement factors were normal, chronic bacteraemia and chronic viral infections could not be detected, and a search for systemic disorders was negative.

A renal biopsy showed severe diffuse segmental glomerulosclerosis and tubular atrophy. The mesangial matrix was increased and immunofluorescence showed IgM within sclerotic areas.

During an episode of drowsiness and vomiting, CSF was examined and protein found to be 152 $\mathrm{mg} / 100 \mathrm{ml}(1.52 \mathrm{~g} / \mathrm{l})$.

In view of the patient's weakness, the persistently raised blood lactate and pyruvate levels, and the raised CSF protein, a mitochondrial myopathy was suspected in addition to his renal problems, and an EMG and a muscle biopsy were performed. EMG and nerve conduction studies did not show any abnormality, but his muscle biopsy showed a few ragged red fibres. Mitochondrial enzyme studies showed some fibres with strongly positive periodic acid-Schiff and succinate dehydrogenase activity increased in some fibres.

The boy's renal function deteriorated and he died at age 3 years.

Family history. A family history of mitochondrial myopathy with ragged red fibres (ophthalmoplegia plus) was found in Cases 4 and 10.

The mother of Case 4 had first noted weakness in her arms and legs at 44 years, which progressed rapidly. Two years later she had difficulty getting up from her bed and raising her arms to do her hair. She was thought to have polymyositis and was treated with steroids. There was improvement in her 
condition but during the following years she developed bilateral pyramidal signs, cogwheel rigidity, and epileptic fits. She was confined to a wheelchair 3 years after symptoms appeared and died 9 years later. A muscle biopsy taken during the 3rd year of her illness showed ragged red fibres.

The 1st-cousin of Case 10 was investigated for short stature at 5 years; at 10 years sensorineural hearing loss and ataxia were noted. A muscle biopsy showed ragged red fibres. Her mother and her mother's sister had muscle biopsies. The former was investigated for renal problems, and in view of the family history a muscle biopsy was taken, the results of which were normal. The latter (mother of Case 10) became deaf at 39 years and her muscle biopsy showed mild non-specific myopathic features with 2B fibre atrophy and no ragged red fibres.

The family history shows only monosymptomatic manifestation in relatives of 3 children. In Case 8 one paternal great-uncle and two 1st-cousins on the father's side are deaf. The father of Case 3 suffered from bilateral ptosis and the paternal uncle of Case 9 is said to have been deaf since his early twenties.

Oligosymptomatic manifestation has been found in relatives of 2 children. The maternal grandmother of Case 10 was said to be deaf and ataxic. The mother and maternal grandmother of Case 7 tired easily, one maternal uncle had been weak and deaf since childhood and his daughter was small; all the family members on the mother's side (except the grandfather) were found to have slightly raised CK levels. ${ }^{69}$

Perinatal history. Pregnancy and delivery of all children had been normal and intrauterine movements had been experienced normally by all mothers. Early milestones were delayed in Cases 4, 5, and 13.

Presenting symptoms. Ptosis or ophthalmoplegia was the first neurological symptom to appear in only 2 of the 13 patients (Cases 2 and 3). Hearing loss was first in 3 others (Cases 1, 8, and 10), pigmentary retinopathy in 2 (Cases 5 and 9), ataxia in 2 (Cases 6 and 11), and weakness in 4 (Cases $4,7,12$, and 13).

Non-neurological symptoms appeared even earlier with short stature in 5 cases, hypoplastic anaemia (Case 1), Fanconi's syndrome (Case 8), and diabetes mellitus (Case 5).

Involvement of the nervous system. Ptosis was present in 10 of our patients, ophthalmoplegia in 8. Ophthalmoplegia was preceded by ptosis in each case, generally it was gradual in onset, and initially asymmetrical in 4 cases (Cases 1, 2, 3, and 9). Ophthalmoplegia itself was not noticed by patients or parents until it was nearly total and in each it was diagnosed before any complaint was made. Diplopia caused problems in Case 2, and in the mother of Case 4 who also had ragged red fibres in a muscle biopsy.

Pupillary responses were normal with the exceptions of Case 11, in whom the pupils were fixed to light, and of Case 5, in whom the pupils reacted sluggishly.

A pigmentary retinal degeneration was present in 7 of the children and consisted of granular pigmentation in a linear or reticular arrangement at the periphery with a moth-eaten or pepper-and-salt appearance in Cases 1, 3, 6, 8, 9, and 10 and of bone spiculae in the mid-periphery in Case 5.

Corrected visual acuity was slightly to moderately decreased in Cases 1, 3, 5, 6, 8, 9, and 10 and Case 11 was nearly blind at 7 years.

There was mild concentric restriction of the visual fields in Cases 1, 5, 8, and 9.

Optic atrophy was present in Case 11 and in the mother of Case 4. The retinal vessels were found to be attenuated in Cases 6 and 11 .

Colour vision was intact in all patients. Dark adaptation was subjectively impaired in Cases 5 and 8.

Facial weakness was noticed in 5 children (Cases 4 , $5,6,8$, and 12).

Progressive sensorineural hearing loss was found in 5 cases (Cases 1, 6, 8, 9, and 10).

Two of the children (Cases 2 and 8 ) suffered episodes of vertigo, though no formal vestibular function tests were performed.

A history of dysphagia was given in Cases $\mathbf{2}$ and 8.

Muscle weakness was present in 9 children (Cases $1,3,4,7,8,9,11,12$, and 13) and in the mother of Case 4 . The neck flexors and proximal muscles were the most severely affected but all also had slight peripheral weakness. The degree of weakness was slight to moderate in all but Case 12 who died from respiratory failure due to severe involvement of the respiratory muscles.

There was slight to moderate muscle wasting in 3 children (Cases 7, 10, and 12).

Corticospinal tract involvement was noted in 5 patients and this varied from very brisk reflexes in Cases 8 and 13 to up-going plantars in Cases 3, 4, and 10. The pyramidal signs developed during the illness, tendon and plantar reflexes having been normal when first examined. Pyramidal signs were also present in the mother of Case 4 . Tendon reflexes were initially found to be normal in Cases 2, 6, 10, and 11, and were later absent in Case 11 and depressed in Cases 2, 6, and 10. Reflexes were always depressed in Cases 5 and 7.

Four of the children developed a sensory neuropathy. Case 2 complained of 'pins and needles' in both legs 3 years after ophthalmoplegia was first 
noticed. Initially sensory testing showed loss of vibration sense in both ankles, and gradually during the next few months all modalities of sensation including pain, proprioception, vibration, and light touch were impaired on the arms and legs in a 'glove and stocking' distribution. Four years after the initial symptoms of ophthalmoplegia plus were recognised, Case 10 developed a peripheral neuropathy with reduced sensation to joint position, pain, light touch, and vibration distally on both legs in an asymmetrical distribution. Case 3 had impaired sensation to pin prick on his legs 14 years after manifestation of the first symptoms. Case 1 had impaired sensation to light touch 2 years after presentation of the disease.

Cerebellar signs were found in 11 children and consisted of central and peripheral ataxia, tremor, and scanning speech. Nystagmus was absent from all. There was pronounced asymmetry of ataxia in Case 6. In those who developed a peripheral neuropathy, cerebellar signs were present before any evidence of neuropathy was detected.

Extrapyramidal signs were present in Case 11 who showed choreoathetoeic movements of the extremities and of the mouth. The mother of Case 4 developed cogwheel rigidity.

Two of the children developed partial epilepsy (Cases 4 and 10) and the mother of Case 4 suffered too from epilepsy.

Formal IQ assessments in 6 patients showed a low score of 46 to $73 \%$ in Cases 4, 6, 10, and 11 and a normal IQ in Cases 2 and 7. Of the patients who were not formally assessed Case 13 was very retarded, whereas the others developed normally.

Laboratory findings. CSF was examined in 6 patients. There was no pleocytosis. CSF protein concentration was at the upper limit of normal $(30 \mathrm{mg} / 100 \mathrm{ml})$ in Case 2 and showed raised values of $66-250 \mathrm{mg} / 100 \mathrm{ml}$ $(0 \cdot 66-2 \cdot 5 \mathrm{~g} / \mathrm{l})$ in Cases $1,3,4,6$, and 13. Case 6 had values on repeated testing which rose from 96 to 210 $\mathrm{mg} / 100 \mathrm{ml}(0 \cdot 96$ to $2 \cdot 1 \mathrm{~g} / \mathrm{l})$ during a 9-month period.

CK estimations were moderately raised in Cases 4 , 7 , and 8 ( 3 to 4 times greater than normal), very high in Case 12 (10 times greater than normal), and were normal in the others.

Blood lactate and pyruvate levels were estimated in all except Cases 6 and 13, and found to be raised in Cases 2, 4, 5, and 7. Of those who had normal blood lactate and pyruvate levels, urinary lactate excretion was tested only in Case 8 over 24 hours and was found to be 4 times the normal level.

Plasma amino-acids were normal in Cases 8, 10, and 11 but the concentration of alanine was raised in Cases 7 and 13.

Normal immunoglobulins were present in Cases 1,
$2,3,4,6,10$, and $13 ; \operatorname{IgA}$ and $\operatorname{IgM}$ were raised in Case 11 .

EMG findings suggested a myopathy in Cases 4, 7, 9,11 , and 12 and were normal in all others. None showed denervation. Peripheral nerve involvement was confirmed electrically in Cases 1, 2, and 10.

The ERG was normal at the time of examination in Cases 2, 4, 6, 9, and 12. The amplitude was reduced in Cases $1,3,5,8$, and 10, and was absent in Case 11.

The EEG showed excess of irregular slow activity in Cases 1, 2, 5, 6, 7, 8, 9, 10, 11, and 12 and showed paroxysmal features in Cases 2, 3, 4, and 8.

Neuroradiological findings. Pneumoencephalography and carotid angiography were done in Case 6 and found to be normal. Computerised tomography (CT) scans of the head were performed in 9 patients. In 2 results were normal (Cases 5 and 9). Dilatation of the cortical sulci was noted in Cases 7 and 8. Prominent cerebellar folia and dilatation of the 4th ventricle, compatible with cerebellar atrophy, were found in Case 1, and Case 11 had a prominent suprasellar cistern. In 2 patients (Cases 4 and 10) dilatation of the ventricular system and of the subarachnoid spaces was observed. On follow-up examination 22 months after the initial studies in Case 10 the CT scan showed increase in the degree of diffuse atrophy and areas of low attenuation in the lentiform nuclei, particularly on the right. A leucoencephalopathic process was recognised in Case 2, who had bilateral areas of low attenuation in the internal capsules and around the trigones.

Muscle biopsy. The diagnosis of a mitochondrial disorder was made in all cases by examination of a muscle biopsy. The features of 'ragged red fibres' and increased mitochondrial enzyme activity, shown particularly in the succinate dehydrogenase prepparations, coupled with ultrastructural abnormalities of the mitochondria, are essential for the diagnosis. The numbers of ragged red fibres varied from case to case and were few in some and numerous in others. An increase in glycogen content was noted in some ragged red fibres. No increase in numbers of central nuclei and no increase in endomysial connective tissue was seen in any biopsy. Variation in fibre diameters is often present but not excessive (Figs 1 and 2).

Electron microscopical examination of the muscle biopsies showed a range of structural abnormalities of mitochondria. In some the only abnormality was a proliferation of cristae in enlarged mitochondria; in others paracrystalline inclusions were found. Most showed abnormally structured mitochondria with parallel arrays of cristae. In one patient (Case 4) who 
had intercostal muscle removed during a Nissen's fundoplication at age 17 years, the earlier changes of large mitochondria with proliferation of cristae seen on biopsy at 13 years, appeared to have progressed to the paracrystalline inclusions also seen in her mother's muscle biopsy (Figs 3, 4, and 5).
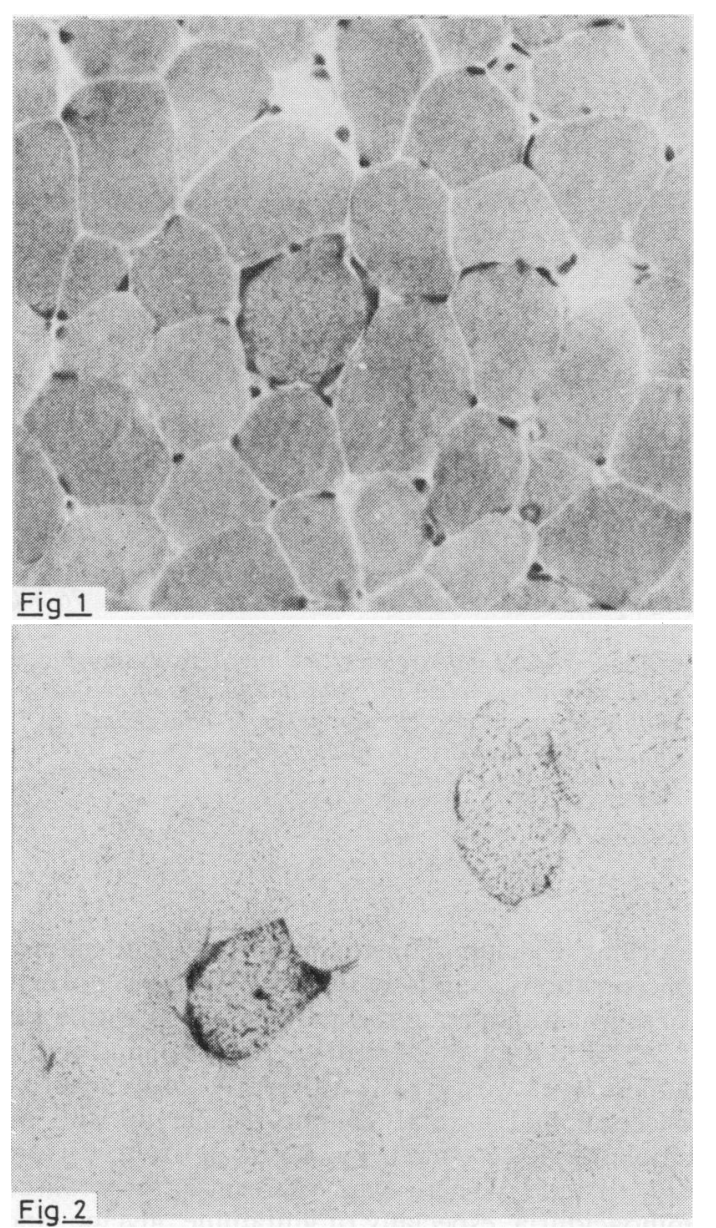

Fig. 1 Muscle biopsy: cryostat section stained with the modified trichrome. A single 'ragged red fibre' is present in the centre. The fibre has increased red staining around the periphery in the subsarcolemmal regions. Apart from some slight variability in fibre diameters no other abnormality is present. $\times 270$.

Fig. 2 Muscle biopsy: cryostat section stained to demonstrate succinate dehydrogenase activity. A short incubation time ( $30 \mathrm{~min})$ shows the ragged red fibres staining strongly with only minimal activity in normal fibres. $\times 270$.
Hypoplastic anaemia. Anaemia (haemoglobin 5.9 g/dl) was clinically apparent in Case 1 by age 9 months. There was no history of previous infection or drug intake, and no other family member was affected. Red cell morphology, white cell, and platelet counts were normal. There was lack of reticulocytosis. Fetal haemoglobin concentration was raised $(1.4 \%$, normal $1 \%)$ as were serum iron levels (33. $1 \mu \mathrm{mol} / 1$ ( $(185 \mu \mathrm{g} / 100 \mathrm{ml})$, normal $14-22 \mu \mathrm{mol} / \mathrm{l})$. Serum iron binding capacity and folic acid levels were normal. The bone marrow showed erythroid hypoplasia and myeloid hyperplasia. $\mathrm{He}$ was investigated for associated congenital abnormalities and a horseshoe kidney was detected. Treatment consisted of repeated transfusions of red blood cells for 3 years and combined steroid and androgen therapy for 6 years, after which time remission occurred.

Heart involvement. Incomplete right-bundle branch block was evident in Case 3 at 13 years and progressed to an arborisation block during the next 5 years. Although subjective symptoms have never been present a pacemaker implantation is now being considered.

Case 7 showed electrocardiographical signs of left ventricular hypertrophy. T-inversion in the left precordial leads was present in Case 10. Cases 5 and 6 had low T-waves.

Endocrinological involvement. Reduced somatic growth was present in all patients. It was noted during the first 3 years of life in all except Case 11, who stopped growing at age 12 years, and Cases 7 and 9, whose height dropped below the 3 rd centile at 5 years.

Skeletal maturation was estimated by bone age in 7 children. It was greatly retarded in all but Case 1, who had corticosteroids and androgen treatment for hypoplastic anaemia.

Growth hormone stimulation tests were done in 5 patients. A normal release was found in Cases 4 and 10. Absence of an appreciable response was detected in Cases 1, 3, and 9. Two of those cases (Cases 3 and 9) were treated with growth hormone, and although their height is still below the 3rd centile, their yearly growth rate doubled.

Three of the patients (Cases 1, 4, and 5) developed diabetes mellitus.

In patients in whom thyroid-stimulating hormone, blood thyroxine, blood cortisol, 17-hydroxy- and 17 oxosteroids were measured, normal results were obtained.

Renal involvement. Two patients developed a chronic progressive glomerulopathy. Case 13 has already been described. In Case 1 the clinical picture during 


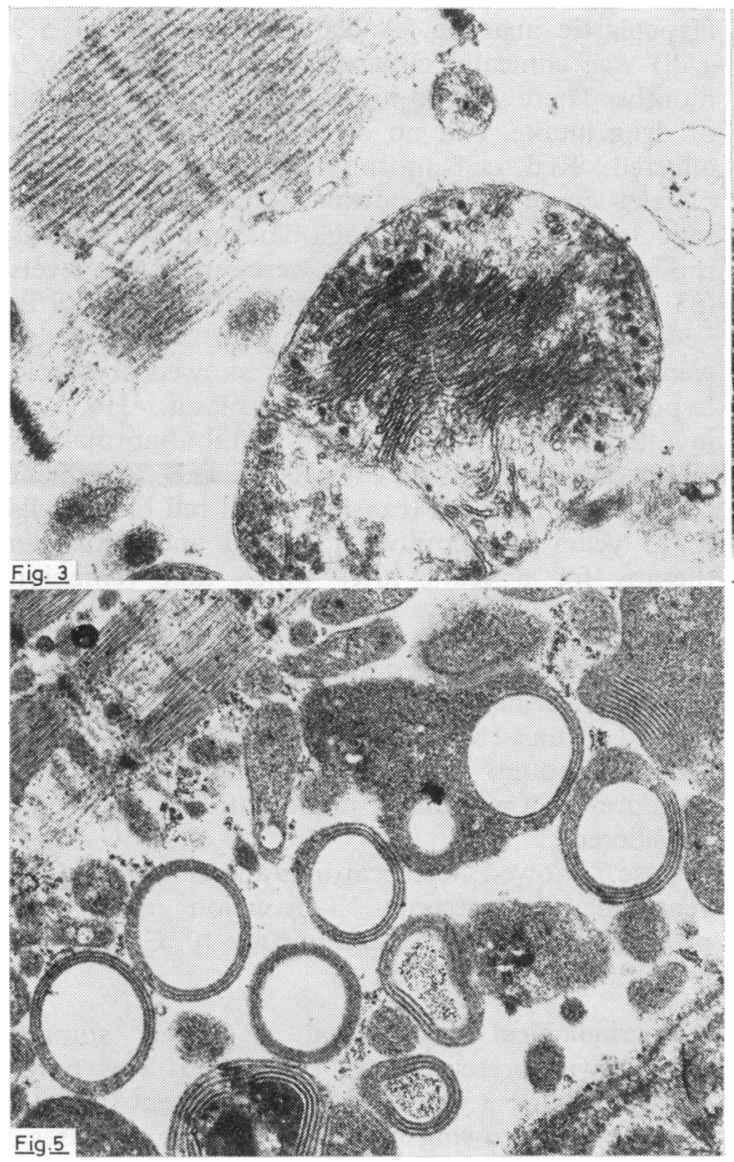

his last year of life was dominated by several episodes of drowsiness, vomiting, and metabolic acidosis. His blood urea and creatinine levels rose, there was hyperkalaemia and isosthenuria, and his EDTA GFR was greatly reduced. No renal biopsy was performed.

In Case 8 at age 1 year, polyuria, polydipsia, and constipation were noted. When she was seen at 18 months, she was dehydrated and mild metabolic acidosis was detected. Her urinary $\mathrm{pH}$ was high $(\mathrm{pH} \mathrm{8.0)}$. There was no proteinuria or glucosuria at this stage. Radiological examination showed a bone age of 9 months. Two months later she was admitted to hospital with hypocalcaemic spasms and having vomited for a few days. Physical findings were mild dehydration and bronchitis. Laboratory examination showed a haemoglobin level of $11.2 \mathrm{~g} / \mathrm{dl}$. The range of serum electrolytes on repeated measurements was 126 to $133 \mathrm{mmol} / \mathrm{l}$ for sodium, $2 \cdot 1$ to $3.8 \mathrm{mmol} / \mathrm{l}$ for potassium, and $106 \mathrm{mmol} / \mathrm{l}$ for

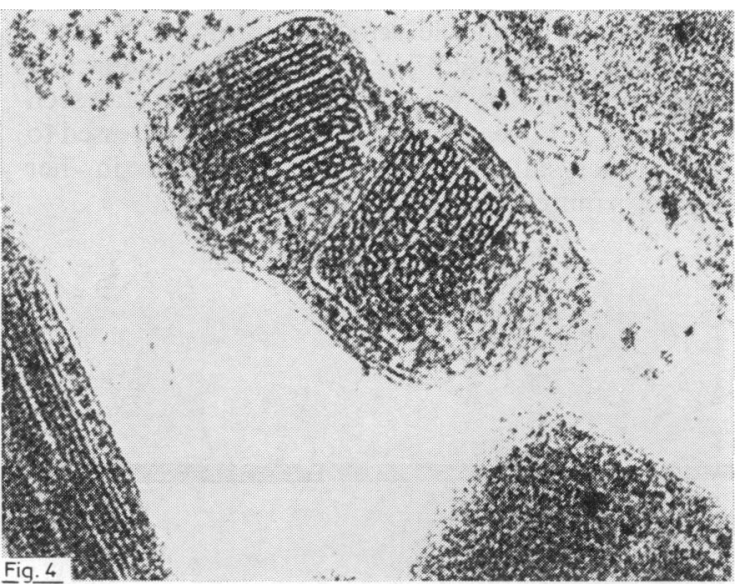

Fig. 3 Muscle biopsy: electron micrograph showing a large mitochondrion with proliferation of cristae. This change is particularly prominent in the younger patients. $\times 25300$.

Fig. 4 Muscle biopsy: electron micrograph showing the paracrystalline arrangement of cristae. This change is found more commonly in the older patients. $\times 76200$.

Fig. 5 Muscle biopsy: electron micrograph showing a group of mitochondria with parallel arrays of cristae mainly arranged in a circular fashion. This change is found in the majority of childhood cases. $\times 10500$.

chloride. Calcium, magnesium, and phosphorus concentrations were low; the urea level was normal. There was a moderate metabolic acidosis with a $\mathrm{pH}$ of 7.27 and $\mathrm{PCO}_{2}$ of $28 \mathrm{mmHg}(3.7 \mathrm{kPa})$, and serum alanine level was greatly raised. A 24-hour urine collection had a total volume of $325 \mathrm{ml}$ and an osmolality of $265 \mathrm{mmol} / \mathrm{kg}$. Urine $\mathrm{pH}$ ranged from $7 \cdot 17$ to $7 \cdot 51$. There was glycosuria, generalised aminoaciduria, especially of glutamine, glycine, and alanine, and increased urinary loss of potassium, calcium, and magnesium. Renal function studies showed a low creatinine clearance of $22-27 \mathrm{ml} / \mathrm{min}$ per $\mathrm{m}^{2}$ (normal 40-90) an increased clearance of phosphate (phosphate excretion index being 0.19 to 0.31 , normal +0.09 to -0.09 ), and loss of bicarbonate at plasma levels above $14.7 \mathrm{mmol} / \mathrm{l}$. There was normal excretion of hydrogen ions evidenced by an adequate ammonia and titrable acidity excretion. On the basis of the clinical and laboratory observations a diagnosis of the de Toni-Debré-Fanconi 
syndrome was made. Underlying diseases-such as cystinosis, tyrosinosis, glycogenosis type I, galactosaemia, fructose intolerance, Wilson's disease, vitamin D deficiency with secondary hyperparathyroidism-were excluded. There was no exposure to heavy metal or antibiotics, and there was no evidence of a renal vascular accident. The patient was discharged on daily supplements of sodium and potassium bicarbonate and a high protein diet. On reinvestigation 8 months later there was some improvement in renal amino-acid and phosphate losses, and bicarbonate reabsorption studies showed appreciable losses only above plasma levels of $22 \mathrm{~mol} / 1$ (normal threshold 24-26). The creatinine clearance was still low and there was now radiological evidence of rickets. This was treated with high doses of vitamin D3 in addition to the bicarbonate substitution. When last seen at age 10 there was still glucosuria and tubular aminoaciduria, but the clinical picture was dominated by neurological deterioration.

\section{Discussion}

In this study it becomes apparent that patients with ragged red fibres present in a variety of ways affecting many systems, causing difficulties in making the diagnosis at presentation. Generally children present initially with short stature. When neurological symptoms appear, the differential diagnosis includes Refsum's disease, A-betalipoproteinaemia, myasthenia gravis, brain stem lesions, Miller-Fisher syndrome, centronuclear myopathy, carnitine deficiency, and Cockayne's syndrome.

Our patients are a somewhat heterogeneous group with ragged red fibres and abnormal muscle mitochondria in common, so do they have the same disease? It appears that mitochondria can only react in a few ways to a large number of influences. ${ }^{16}$ Experiments have shown that infusions of uncouplers of oxidative phosphorylation produce ragged red fibres in muscle ${ }^{72}$ but in the presence of chloramphenicol no ragged red fibres were seen. Hypoxia may also produce similar changes. ${ }^{73}$ Even in a variety of documented disturbances of mitochondrial enzymes ${ }^{17} 46$ 58-62 74 75, the morphological and ultrastructural findings are similar and the clinical presentation of those conditions is varied and non-specific; although the pathological changes in Luft's disease ${ }^{75}$ are similar, the symptoms with hypermetabolism make this a clearly different entity.

It is difficult to ascertain whether the defects are primary or secondary. If the biochemical defect is primary, as perhaps in carnitine deficiency, ${ }^{74}$ the proliferation of cristae and mitochondria could be an attempt to overcome defective function. Alternatively, the changes could be secondary to a chemical or viral insult. ${ }^{14}$ Askanas et al. ${ }^{64}$ showed that the mitochondrial defect was reproduced in muscle cell cultures and suggested the following possibilities: (1) A genetic defect of formation of mitochondrial proteins governed by mitochondrial or nuclear DNA. (2) A genetic defect of nuclear DNA-directed formation of a component, which in turn results in defective mitochondria. (3) An occult infection, transmitted vertically or horizontally from cell-to-cell or mitochondrion to mitochondrion.

Genetic considerations are complicated in our patients for reasons concerning the primary defect(s), which is unknown and may differ from patient to patient. An autosomal dominant inheritance with variable expressivity seems likely in most of them. This is exemplified in particular in Case 7, whose family tree was presented by Tarlow et al. ${ }^{69}$ Autosomal recessive cases already reported and sporadic ones could also be explained on this basis.

Whether morphological or biochemical abnormalities are inherited, or whether an inherited disposition makes the body react with the reported morphological, biochemical, and clinical features to a still unknown factor remains unanswered. However, although it does not contradict the suggested inheritance, it is interesting that symptoms appeared at roughly the same time in mother and daughter in Case 4, lending support to the theory of an infection as the primary cause.

Mitochondrial abnormalities have been encountered in different organs. $^{613163145495257}$ The common involvement of the nervous system, musculature, heart, gastrointestinal tract, and the endocrinological system is therefore not surprising. Furthermore, one could expect renal tubular dysfunction to occur more frequently, since tubular reabsorption and secretions are highly dependent on the activity of mitochondrial enzymes. The de Toni-Debré-Fanconi syndrome was reported recently in 2 infants with abnormal mitochondria, lactic acidosis, weakness, and deficiencies in cytochrome c oxidase and cytochrome aa3. ${ }^{6162}$ This seems to be different from our patient (Case 8), however we cannot speculate further on this interesting combination, not having material available for electron microscopical examination and enzyme studies.

The same applies for the combination of hypoplastic anaemia and mitochondriopathy. It was recently shown that hypoplastic anaemia is due to a defect of the haematopoietic microenvironment, ${ }^{76}$ and a disturbed communication between hypothetical 'nurse cells' and haematopoietic stem cells was suggested. ${ }^{77}$ Could a mitochondrial defect in our 
patient with hypoplastic anaemia have disturbed the haematopoietic microenvironment?

It is quite possible that the glomerulopathy in 2 of our patients and the factor causing the mitochondriopathy are unrelated. However, it is surprising that this combination was present in 2 out of 13 patients and it is tempting to think that one lesion-for example, an unrecognised viral infection-is responsible for both conditions.

Since the defects are not known, treatment is symptomatic. The most important seems early pacemaker implantation in heart conduction defects and it seems wise to perform ECGs regularly, since conduction defects may appear without warning and not until much later in the course of the disease. ${ }^{14} 1952$ Failure to do this can end dramatically. ${ }^{318} 23242642$

In 2 patients (Cases 10 and the mother of Case 4) who were given steroids for other reasons, ataxia decreased and there was some improvement in strength. Deterioration followed when steroids were stopped. On a short trial of steroids in Case 12, CK levels became normal, only to increase again when they were stopped because of side effects.

Carbon dioxide retention was a continuing problem in Case 12, whose quality of life could have been improved by use of a cuirass over night (J Newsom-Davies, 1980, personal communication).

Evidence of growth hormone deficiency has been reported, ${ }^{2634}$ and one patient received growth hormone treatment without effect. ${ }^{34}$ Case 9 has been receiving growth hormone for 10 months without any great improvement, and despite 5 years of treatment in Case 3, although his growth velocity increased by $3 \mathrm{~cm}$ a year at age 14 years, his height and weight remain below the 3rd centile.

Patients who developed diabetes mellitus require treatment with insulin.

We have presented these patients because, although the disorder is well documented in adults, there are few recorded cases in children. Their varied presentation and lack of the complete syndrome until later cause difficulties in making the diagnosis.

We hope this report will draw to the attention of paediatricians a disorder which may be more common than realised.

\section{Addendum}

Since this paper was submitted we have seen 4 more patients with mitochondrial cytopathy. All had short stature. The first (aged 12 years) presented with deafness, weakness, and ptosis. The second (aged 7 years) had proximal renal tubular acidosis, deafness, ptosis, and a pigmentary retinopathy. His mother is short and has ptosis and a myopathic
EMG. The third patient (aged 12 years) presented at 8 months with hypoplastic anaemia, and later (aged 6 years) a diagnosis of nephronopthisis with tapetoretinal degeneration (Senior's syndrome) was made. She developed diabetes, weakness, deafness, and dementia during the last 2 years. The most recent patient (aged 15 years) had bilateral cataracts at 3 years, developed intractible fits at 7 years, and was later shown to have leucodystrophic changes on CT scan at 8 years. He became hypothyroidotic at age 9 years. There is a strong family history of renal disease in this patient; 4 relatives on the maternal side have been affected and have died from renal failure.

Case 12 has recently developed extrapyramidal signs.

These wide ranging symptoms confirm our conclusion that mitochondrial cytopathy is a complex disorder that may be fairly common.

We thank Dr E M Brett, Dr M J Dillon, Dr D Grant, and Dr J T Harries for permission to study their patients, and colleagues from other hospitals who referred the other patients.

\section{References}

1 Olson W, Engel W K, Walsh G O, Einaugler R. Oculocraniosomatic neuromuscular disease with 'ragged-red fibres'. Arch Neurol 1972; 26: 193-211.

2 Drachman D A. Ophthalmoplegia plus. The neurodegenerative disorders associated with progressive external ophthalmoplegia. Arch Neurol 1968; 18: 654-74.

3 Kearns T P, Sayre G P. Retinitis pigmentosa, external ophthalmoplegia, and complete heart block. Unusual syndrome with histologic study in one of two cases. Arch Ophthal 1958; 60: 280-9.

4 Galezowski F. Paralysie de tous les muscles de l'oeil dans l'ataxie. Rev Ophtalmol 1878; 1 : 88-90.

5 Sandifer P H. Chronic progressive ophthalmoplegia of myopathic origin. J Neurol Neurosurg Psychiatry 1946; 9: 81-3.

- Bastiaensen L A K, Joosten E M G, De Rooij J A M, et al. Ophthalmoplegia-plus; a real nosological entity. Acta Neurol Scand 1978; 58: 9-34.

7 Levíc Z M, Stefanovíc B S, Nicolic M Z, Pišteljic D T. Progressive nuclear ophthalmoplegia associated with mental deficiency, lingua scrotalis, and other neurologic and ophthalmologic signs in a family. Neurology (Minneap) 1975; 25 : 68-71.

8 Gomez M R, Engel A G, Dyck P J. Progressive ataxia, retinal degeneration, neuromyopathy, and mental subnormality in a patient with true hypoparathyroidism, dwarfism, malabsorption, and cholelithiasis. Neurology (Minneap) 1972; 22: 849-55.

- Shapira Y, Cederbaum S D, Nielsen D. Familial progressive degeneration of the cerebral grey matter with ragged red myopathy (abstract). Neurology (Minneap) $1974 ; 24: 366$.

10 Lake B D, Ashby M, Wilson J. Dominantly inherited mitochondrial disease with neurological and myopathic abnormalities. In: Bradley W G, ed. Abstracts of papers presented at the Third International Congress on Muscle 
Diseases, Newcastle-upon-Tyne 1974. International Congress Series, No 334. Amsterdam: Excerpta Medica, 1974: 18-9.

11 McLeod J G, Baker W de C, Shorey C D, Kerr C B. Mitochondrial myopathy with multisystem abnormalities and normal ocular movements. J Neurol Sci 1975; 24: 39-52.

12 Simopoulos A P, Delea C S, Bartter F C. Neurodegenerative disorders and hyperaldosteronism. J Pediatr 1971; 79 : 633-41.

13 Schneck L, Adachi M, Briet P, Wolintz A, Volk B W. Ophthalmoplegia plus with morphological and chemical studies of cerebellar and muscle tissue. J Neurol Sci 1973; 19: $37-44$.

14 Berenberg R A, Pellock J M, DiMauro S, et al. Lumping or splitting? Ophthalmoplegia plus or Kearns-Sayre syndrome? Ann Neurol 1977; 1: 37-54.

15 Kamieniecka Z. Myopathies with abnormal mitochondria. A clinical, histological, and electrophysiological study. Acta Neurol Scand 1977; 55: 57-75.

16 Karpati G, Carpenter S, Larbrisseau A, Lafontaine R. The Kearns-Shy syndrome. A multisystem disease with mitochondrial abnormality demonstrated in skeletal muscle and skin. J Neurol Sci 1973; 19: 133-51.

17 Spiro A J, Moore C L, Prineas J W, Strasberg P M, Rapin I. A cytochrome-related inherited disorder of the nervous system and muscle. Arch Neurol 1970; 23: 103-12.

18 Tridon P, Martin J J, Vidailhet M, Floquet J, Philippart M, Nelmann N. Spongiose cérèbrale juvenile. Pediatrie 1974; 29 : 235-47.

19 Butler I J, Gadoth N. Kearns-Sayre syndrome. A review of a multisystem disorder of children and young adults. Arch Intern Med 1976; 136: 1290-3.

20 D'Agostino A N, Ziter F A, Rallison M L, Bray P F. Familial myopathy with abnormal muscle mitochondria. Arch Neurol 1968; 18: 388-401.

21 Markesbery W R. Lactic acidemia, mitochondrial myopathy, and basal ganglia calcification. Neurology (Minneap) 1979; 29: 1057-61.

22 Tsairis P, Engel W K, Kark P. Familial myoclonic epilepsy syndrome associated with skeletal muscle mitochondrial abnormalities (abstract). Neurology (Minneap) 1973; 23: 408.

23 Daroff R B, Solitare G B, Pincus J H, Glaser G H. Spongiform encephalopathy with chronic progressive external ophthalmoplegia. Central ophthalmoplegia mimicking ocular myopathy. Neurology (Minneap) 1966; 16: 161-9.

24 Castaigne P, Lhermitte F, Escourolle R, et al. Etude anatomo-clinique d'une observation d'ophtalmoplégie plus avec analyse des lesions musculaires, nerveuses centrales, oculaires, myocardiques, et thyroïdiennes. Rev Neurol (Paris) 1977; 133: 369-86.

25 Bertorini T, Engel W K, Di Chiro G, Dalakas M. Leukoencephalopathy in oculocraniosomatic neuromuscular disease with ragged-red fibers. Arch Neurol 1978; 35: 643-7.

26 Voisin M, Marty-Double C, Grolleau R, Bassius C, Dumas R, Jean R. Syndrome de Kearns. Arch Fr Pediatr 1980; 37: 119-21.

27 Rowland L P, Berenberg R A, Crosby T W, Chou S M. Letter: Diagnosis of Leigh's disease questioned, defended. Neurology (Minneap) 1974; 24 : 598-9.

28 Azubuike J C, Gullotta F, Kallfelz H C. Juvenile spongiöse dystrophy des ZNS mit Medullanekrose. Neuropaediatrie $1975 ; 6: 292-306$.

29 Croft P B, Cutting J C, Jewesbury E C O, Blackwood W, Mair W G P. Ocular myopathy (progressive external ophthalmoplegia) with neuropathic complications. Acta Neurol Scand 1977; 55: 169-97.
30 Danta G, Hilton R C, Lynch P G. Chronic progressive external ophthalmoplegia. Brain 1975; 98: 473-92.

31 Peyronnard J M, Charron L, Bellavance A, Marchand L. Neuropathy and mitochondrial myopathy. Ann Neurol 1980; 7: 262-8.

32 Shy G M, Silberberg D H, Appel S H, Mishkin M M, Godfrey E H. A generalised disorder of nervous system, skeletal muscle, and heart resembling Refsum's disease and Hurler's syndrome. I. Clinical, pathologic, and biochemical characteristics. Am J Med 1967; 42: 163-8.

33 Haas J, Haller P, Patzold U. Das Kearns-Syndrom, eine Symptomkombination von chronisch progressiver externer Ophthalmoplegie, Pigmentdegeneration der Retina und Reizleitungsstörungen des Herzens. Dtsch Med Wochenschr 1976; 101 : 1523-8.

34 Boltshauser E, Jerusalem F, Niemeyer G, Huber C. Kearns-Syndrom. Progressive externe Ophthalmoplegie, Pigmentdegeneration der Retina und kardiale Reizleitungsstörungen. Schweiz Med Wochenschr 1977; 107: $1880-8$.

35 Heycock J B, Wilson J. Diabetes mellitus in a child showing features of Refsum's syndrome. Arch Dis Child 1958 ; 33: 320-2.

36 Bastiaensen L A K, Jasper H H J, Stadhouders A M, Egberink G J M, Korten J J. Chronic progressive external ophthalmoplegia in a heredo-ataxia: neurogenic or myogenic? Acta Neurol Scand 1977; 56: 483-507.

37 Sahashi K, Yashima F, Hirose K, et al. Case of oculocraniosomatic neuromuscular disease associated with Parkinsonism with special reference to catecholamine metabolism (abstract). Rinsho Shinkeigaku 1976; 16: 235-43.

38 Lakin M, Locke S. Progressive ocular myopathy ovarian insufficiency and diabetes mellitus. Report of case. Diabetes $1961 ; 10$ : 228-31.

39 Lowes M. Chronic progressive external ophthalmoplegia, pigmentary retinopathy, and heart-block (Kearns-Sayre syndrome). Report of a case. Acta Ophthalmol (Kbh) 1975; 53: 610-9.

40 Kaefer O. Proportionierter Zwergwuchs in Verbindung mit okulaerer Myopathie, rezidivierenden Hornhoutoedemen, tapetoretinaler Degeneration, und Diabetes Mellitus. Ber Dtsch Ophthalmol Ges 1975; 73: 618-20.

41 Toppet M, Telerman-Toppet N, Szliwowski H B, Vainsel M, Coers C. Oculocraniosomatic neuromuscular disease with hypoparathyroidism. Am J Dis Child 1977; 131 : 437-41.

42 Seigel A M, Shaywitz B A. Ciesielski T. Kearns-Sayre syndrome; the importance of early recognition. Am J Dis Child 1977; 131: 711-2.

43 Robertson W C, Visekul C, Lee Y E, Lloyd R V. Basal ganglia calcification in Kearns-Sayre syndrome. Arch Neurol 1979; 36: 711-3.

44 Pellock J M, Behrens M, Lewis L, et al. Kearns-Sayre syndrome and hypoparathyroidism. Ann Neurol 1978; 3: 455-8.

45 Hackett T N, Jr, Bray P F, Ziter F A, Nyhan W L, Creer $\mathbf{K}$. A metabolic myopathy associated with chronic lactic acidemia, growth failure, and nerve deafness. J Pediatr 1973; 83: 426-31.

46 Monnens L, Gabreëls F, Willems J A. Letter: A metabolic myopathy associated with chronic lactic acidemia, growth failure, and nerve deafness. J Pediatr 1975; 86: 983.

47 Shy G M, Gonatas N K, Perez M. Two childhood myopathies with abnormal mitochondria. I. Megaconial myopathy. II. Pleconial myopathy. Brain 1966; 89: 133-58.

48 Okamura K, Santa Y, Nagae K, et al. Congenital oculoskeletal myopathy with abnormal muscle and liver mitochondria. J Neurol Sci 1976; 27 : 79-91. 
49 Gonatas N K, Evangelista I, Martin J. A generalised disorder of nervous system, skeletal muscle, and heart resembling Refsum's disease and Hurler's syndrome. Ultrastructure. Am J Med 1967; 42: 169-78.

50 Rawles J M, Weller R O. Familial association of metabolic myopathy, lactic acidosis, and sideroblastic anemia. Am J Med 1974; 56: 891-97.

51 Kearns T P. External ophthalmoplegia, pigmentary degeneration of the retina, and cardiomyopathy: a newly recognised syndrome. Trans Am Ophthalmol Soc 1965; 63: 559-625

52 McComish M, Compston A, Jewitt D. Cardiac abnormalities in chronic progressive external ophthalmoplegia. Br Heart J 1976; 38: 526-9.

53 DiMauro S, Schotland D L, Bonilla E, Lee C P, Gambetti P, Rowland L P. Progressive ophthalmoplegia, glycogen storage, and abnormal mitochondria. Arch Neurol 1973; 29: 170-9.

54 Iannaccone S T, Griggs R C, Markersbery W R, Joynt R J. Familial progressive external ophthalmoplegia and ragged red fibres. Neurology (Minneap) 1974; 24: 1033-8.

55 Morgan Hughes J A, Mair W G P. Atypical muscle mitochondria in oculoskeletal myopathy. Brain 1973; 96: 215-24.

56 DiMauro S, Schotland D L, Bonilla E, Lee C P, DiMauro P M M, Scarpa A. Mitochondrial myopathies: which and how many? In: Milhorat A T, ed. Exploratory concepts in muscular dystrophy. II. Excerpta Medica Congress Series, No 333. Amsterdam: Excerpta Medica, 1974: 506-15.

57 Harati Y, Patten P M, Sheehan M, et al. Cardiac biopsy in Kearns-Sayre syndrome (abstract). In: den Hartog Jager W A, Bryn G W, Heystee A P J, eds. Neurology: Proceedings of the Eleventh World Congress of Neurology. International Congress Series, No 434. Amsterdam: Excerpta Medica, 1977: 318.

58 Morgan Hughes J A, Darveniza P, Kahn S N, et al. A mitochondrial myopathy characterised by a deficiency in reducible cytochrome B. Brain 1977; 100: 617-40.

59 Schotland D L, DiMauro S, Bonilla E, Scarpa A, Lee C P. Neuromuscular disorder associated with a defect in mitochondrial energy supply. Arch Neurol 1976; 33:475-9.

60 Morgan Hughes J A, Darveniza P, Landon D N, Lane J M, Clark J B. A mitochondrial myopathy with a deficiency of respiratory chain NADH-CoQ reductase activity. $J$ Neurol Sci $1979 ; 43$ : 27-46.

61 Van Biervliet J P G M, Brunivis L, Ketting D, et al. Hereditary mitochondrial myopathy with lactic acidemia, a De Toni-Fanconi-Debré syndrome, and a defective respiratory chain in voluntary striated muscles. Pediatr Res 1977; 11 : 1088-93.

62 DiMauro S, Mendell J R, Sahenk Z, et al. Fatal infantile mitochondrial myopathy and renal dysfunction due to cytochrome C oxidase deficiency. Neurology (Minneap) $1980 ; 30$ : 795-804.
63 Kark R A P, Rodriguez-Budelli M M. Clinical correlations of partial deficiency of lipoamide-dehydrogenase. Neurology (Minneap) 1979; 29: 1006-13.

64 Askanas V, Engel W K, Britton D E, Adornato B T, Eiben $\mathbf{R}$ M. Reincarnation in cultured muscle of mitochondrial abnormalities. Two patients with epilepsy and lactic acidosis. Arch Neurol 1978; 35 : 801-9.

65 Kiloh L G, Nevin S. Progressive dystrophy of the external ocular muscles (ocular myopathy). Brain $1951 ; 74: 115-43$.

66 Lind I, Prame G. Chronic progressive external ophthalmoplegia and muscular dystrophy. Acta Ophthal (Kbh) $1963 ; 41$ : 497-507.

67 Jankowicz E, Berger H, Kurasz S, Winogrodzka W, Eljase L. Familial progressive external ophthalmoplegia with abnormal mitochondria. Eur Neurology 1977; 15: 318-24.

68 Lambert C D, Fairfax A J. Neurological associations of chronic heart block. J Neurol Neurosurg Psychiatry 1976; 39: 571-5.

69 Tarlow M J, Lake B D, Lloyd J K. Chronic lactic acidosis in association with myopathy. Arch Dis Child 1973; 48: 489-92.

70 Schnitzler E R, Robertson W C, Jr. Familial KearnsSayre syndrome. Neurology (Minneap) 1979; 29: 1172-4.

71 Claireaux A E, Lake B D. Muscle disorders in the floppy child. In: Rosenberg H S, Bolande R P, eds. Perspectives in paediatric pathology. Vol. 4. New York: Year Book Medical Publishers, 1978: 349-86.

72 Melmed C, Karpati G, Carpenter S. Experimental mitochondrial myopathy with 'ragged-red' fibers (abstract). Neurology (Minneap) 1974; 24: 353

73 Heffner R R, Barron S A. The early effects of ischemia upon skeletal muscle mitochondria. J Neurol Sci 1978; 38 : 295-315.

74 Karpati G, Carpenter S, Engel A G, et al. The syndrome of systemic carnitine deficiency. Clinical, morphological, biochemical, and pathophysiologic features. Neurology (Minneap) 1975; 25: 16-24.

75 Luft R, Ikkos D, Palmieri G, Erstner L, Afzelius B. A case of severe hypermetabolism of nonthyroid origin with a defect in the maintenance of mitochondrial respiratory control. A correlated clinical, biochemical, and morphological study. J Clin Invest 1962; 41 : 1776-804.

76 Ershler W B, Ross J, Finlay J L, Shahidi N T. Bone marrow microenvironment defect in congenital hypoplastic anemia. $N$ EnglJ Med 1980; 302: 1321-7.

77 Boggs $\mathrm{D}$ R. The hematopoietic microenvironment. N Engl J Med 1980; 302: 1359-60.

Correspondence to Dr B D Lake, Department of Histopathology, The Hospital for Sick Children, Great Ormond Street, London WC1N 3JH.

Received 23 January 1981 